\title{
Percepção dos profissionais, professores e estudantes da área da saúde quanto ao trabalho em equipes multiprofissionais e a geração e compartilhamento de informações
}

\author{
Patricia Ester Fendrich, Sandra Aparecida Furlan, Aline Andreia Marques Volkweis
}

\begin{abstract}
Resumo
Gestão do conhecimento (GC) é inovação, em especial no trabalho em equipes. Segundo Stefano et al. (2014), GC é um conjunto de processos para produção e difusão do conhecimento em organizações. Trabalho em equipes é aquele constituído por profissionais de diferentes formações, que estão dispostos a ensinar, aprender e compartilhar de maneira colaborativa. Este estudo teve por objetivo analisar a percepção dos profissionais, professores e estudantes da área da saúde vinculados a Univille quanto ao trabalho em equipes e a gestão do conhecimento. A pesquisa foi do tipo exploratória e utilizou como instrumento um formulário Googledocs, com afirmações e três categorias de respostas. Responderam ao questionário onze profissionais de saúde, dezenove professores e duzentos e noventa e seis estudantes. Os participantes teriam que ter vínculo com os cursos da área da saúde da Univille e Atenção Básica. Os resultados indicam que 100\% dos professores e profissionais da saúde e $90,8 \%$ dos estudantes concordam que é importante o incentivo ao trabalho em equipes. Quando perguntados se o trabalho multiprofissional contribui para gerar novos conhecimentos, $87,1 \%$ dos estudantes e $100 \%$ dos professores e profissionais concordaram que sim. Sobre o compartilhamento de informações, $100 \%$ dos profissionais que responderam ao instrumento, concordam que o trabalho multiprofissional em saúde contribui para o compartilhamento de informações. Já a maior parte dos professores (55\%) e dos estudantes $(39,5 \%)$, responderam que não concordam e nem discordam dessa afirmação. Com estes resultados é possível inferir que há consenso quanto a importância do incentivo ao trabalho em equipes multiprofissionais de saúde e que esse contribui para gerar novos conhecimentos, A fragilidade encontrada está no compartilhamento de informações o que sugere a necessidade de se estabelecer processos que possam garantir a disseminação do que é produzido entre os profissionais, estudantes e professores.
\end{abstract}

Descritores: Gestão do Conhecimento, Equipes multiprofissionais, Saúde, Formação 